\title{
Osteoarthritis guidelines: a progressive role for topical nonsteroidal anti-inflammatory drugs
}

This article was published in the following Dove Press journal:

Journal of Multidisciplinary Healthcare

3 April 2013

Number of times this article has been viewed

\section{Steven P Stanos}

Rehabilitation Institute of Chicago,

Center for Pain Management,

Chicago, IL, USA
Correspondence: Steven P Stanos Rehabilitation Institute of Chicago, Center for Pain Management, 980 N Michigan Avenue, Suite 800, Chicago, IL 606II, USA

Tel + I 3/2 2387809

Fax + I 3122387801

Email stanos.steven@gmail.com

\begin{abstract}
Current treatment guidelines for the treatment of chronic pain associated with osteoarthritis reflect the collective clinical knowledge of international experts in weighing the benefits of pharmacologic therapy options while striving to minimize the negative effects associated with them. Consideration of disease progression, pattern of flares, level of functional impairment or disability, response to treatment, coexisting conditions such as cardiovascular disease or gastrointestinal disorders, and concomitant prescription medication use should be considered when creating a therapeutic plan for a patient with osteoarthritis. Although topical nonsteroidal anti-inflammatory drugs historically have not been prevalent in many of the guidelines for osteoarthritis treatment, recent evidence-based medicine and new guidelines now support their use as a viable option for the clinician seeking alternatives to typical oral formulations. This article provides a qualitative review of these treatment guidelines and the emerging role of topical nonsteroidal anti-inflammatory drugs as a therapy option for patients with localized symptoms of osteoarthritis who may be at risk for oral nonsteroidal anti-inflammatory drugrelated serious adverse events.
\end{abstract}

Keywords: osteoarthritis, nonsteroidal anti-inflammatory drugs, guidelines, topical analgesics, diclofenac

\section{Introduction}

Osteoarthritis is the most common type of arthritis in the United States and poses an estimated annual cost of more than $\$ 185$ billion to the national health care system. ${ }^{1,2}$ This clinical disorder affects $33.6 \%$ of adults older than 65 years of age, ${ }^{1,3}$ and the prevalence rate increases significantly with age. ${ }^{4}$ Osteoarthritis progresses over time and may present with loss of articular cartilage, bone remodeling, and structural atrophy in the affected joints, resulting in chronic pain, stiffness, and limits on physical function. ${ }^{5}$ Clinical practice in the management of symptoms associated with osteoarthritis incorporates a variety of nonpharmacologic approaches in addition to pharmacologic therapeutic options, including the use of nonsteroidal anti-inflammatory drugs (NSAIDs).

Since the approval of indomethacin in 1962, NSAIDs have become an established form of treatment for chronic pain associated with osteoarthritis. ${ }^{6}$ Although effective, oral formulations of these products have been associated with serious adverse gastrointestinal, cardiovascular, and renal events. ${ }^{6}$ Furthermore, older age can increase these risks. ${ }^{7}$ When prescribing NSAIDs for the management of chronic pain associated with osteoarthritis, clinicians must balance efficacy and safety when determining treatment, particularly in older patients. 
Current guidelines for the treatment of chronic pain associated with osteoarthritis reflect the collective clinical knowledge of international experts in weighing the benefits of pharmacologic therapy options while striving to minimize the negative effects associated with them. Treatment guidelines include topical formulations of NSAIDs as a therapy option for patients with localized symptoms of osteoarthritis who may be at risk for oral NSAID-related serious adverse events, such as older patients. This article provides a qualitative examination of several of these treatment guidelines and reviews the emerging role of topical NSAIDs in the osteoarthritis treatment landscape.

\section{Guidelines}

\section{American Academy of Orthopaedic} Surgeons (AAOS)

In 2008, the AAOS released guidelines for the treatment of osteoarthritis of the knee (Table 1). ${ }^{8}$ For patients suffering from chronic pain associated with osteoarthritis of the knee, the AAOS recommends initially implementing nonpharmacologic measures to provide pain relief, including physical therapy, low-impact or strengthening exercises, patellar taping, and weight loss for overweight patients. For patients who do not receive adequate pain relief through these therapeutic options, the AAOS recommends the use of acetaminophen ( $\leq 4000 \mathrm{mg} /$ day) or oral NSAIDs. However, the guidelines note that patients who are at increased risk for gastrointestinal adverse events should avoid the use of oral NSAIDs. Risk factors include age 60 years or older, preexisting comorbid medical conditions, history of peptic ulcer disease or gastrointestinal bleeding, and concomitant use of corticosteroids or anticoagulants. ${ }^{8}$ Patients who are at increased risk for gastrointestinal adverse events should receive acetaminophen, nonselective oral NSAIDs with a gastroprotective agent, cyclooxygenase-2 inhibitors, or topical NSAIDs. The AAOS asserts the statistically significant improvements in pain relief, stiffness, and physical function with topical NSAIDs while noting that additional studies are required to establish clinical improvements. ${ }^{8}$ For short-term pain relief from osteoarthritis of the knee, the AAOS suggests intra-articular corticosteroid administration.

\section{National Institute for Health and Clinical Excellence (NICE)}

The Europe-based NICE released guidelines in 2008 for the care and management of adults with osteoarthritis (Table 1). ${ }^{9}$ NICE recommends an initial consideration of nonpharmacologic therapy to relieve pain, including patient education, strengthening or aerobic exercise, manual physiotherapy, and

Table I Topical NSAIDs in clinical treatment guidelines for OA

\begin{tabular}{|c|c|}
\hline Guideline & Treatment recommendation \\
\hline $\begin{array}{l}\text { American Academy of Orthopaedic } \\
\text { Surgeons, } 2008^{8}\end{array}$ & $\begin{array}{l}\text { Knee OA: patients with symptomatic knee OA and increased risk for Gl adverse events (age } 60 \text { years or } \\
\text { older, comorbid medical conditions, history of peptic ulcer disease or Gl bleeding, and/or concomitant } \\
\text { use of corticosteroids or anticoagulants) should receive one of the following analgesics for pain } \\
\text { - acetaminophen ( } \leq 4000 \mathrm{mg} / \text { day) } \\
\text { - topical NSAIDs } \\
\text { - nonselective oral NSAIDs plus gastroprotective agent } \\
\text { - COX-2 inhibitors }\end{array}$ \\
\hline $\begin{array}{l}\text { National Institute for Health and Clinical } \\
\text { Excellence, } 2008^{9}\end{array}$ & $\begin{array}{l}\text { Hand or knee OA: acetaminophen or topical NSAIDs should be considered as first-line pharmacologic } \\
\text { therapy after nonpharmacologic therapy. Acetaminophen or topical NSAIDs should be considered } \\
\text { ahead of oral NSAIDs, COX- } 2 \text { inhibitors, or opioids as first-line pharmacologic therapies }\end{array}$ \\
\hline American College of Rheumatology, $2012^{10}$ & $\begin{array}{l}\text { Hand OA: first-line pharmacologic therapy for hand OA should include one or more of the following } \\
\text { - topical NSAIDs, including trolamine salicylate } \\
\text { - oral NSAIDs, including COX-2 inhibitors } \\
\text { - topical capsaicin } \\
\text { - tramadol } \\
\text { Knee OA: first-line pharmacologic therapy for knee OA should include one of the following } \\
\text { - acetaminophen } \\
\text { - topical NSAIDs } \\
\text { - oral NSAIDs } \\
\text { - tramadol } \\
\text { - intra-articular corticosteroid injections } \\
\text { Patients aged } 75 \text { years or older with hand or knee OA should receive topical rather than oral } \\
\text { NSAIDs }\end{array}$ \\
\hline
\end{tabular}

Abbreviations: COX, cyclooxygenase; GI, gastrointestinal; NSAID, nonsteroidal anti-inflammatory drug; OA, osteoarthritis. 
weight loss for obese or overweight patients. For patients who require further therapy, NICE recommends acetaminophen or topical NSAIDs as first-line pharmacologic therapy for osteoarthritis of the hand or knee. The organization cites the decreased systemic absorption of the active ingredient with the use of topical formulations as the primary reason for their place in the guidelines, as a factor that may result in fewer systemic adverse events. Acetaminophen or topical NSAIDs are recommended ahead of oral NSAIDs, cyclooxygenase- 2 inhibitors, or opioid medications as firstline pharmacologic therapies. NICE further suggests that physicians consider an individual's risk for adverse events, including advanced age, before prescribing oral NSAIDs, and that they coprescribe a proton pump inhibitor to avoid gastrointestinal adverse events.

\section{American College of Rheumatology (ACR)}

The ACR recently updated their guidelines using a systematic literature review and a formal grading process involving experts from numerous disciplines to develop evidencebased recommendations (Table 1). ${ }^{10}$ The 2012 guidelines include both nonpharmacologic and pharmacologic recommendations for osteoarthritis of the hand, knee, and hip. Nonpharmacologic therapy recommendations are similar to those of AAOS and NICE and include exercise, weight loss, and patient education. Pharmacologic therapy recommendations in the new guidelines place an increased emphasis on the use of topical NSAIDs. For osteoarthritis of the hand, the recommendations include topical NSAIDs, topical capsaicin, oral NSAIDs, or tramadol as first-line pharmacologic therapy. For osteoarthritis of the knee, the ACR recommends acetaminophen, topical NSAIDs, oral NSAIDs, tramadol, or intra-articular corticosteroid injections as first-line pharmacologic therapy. For patients aged 75 years or older with osteoarthritis of the hand or knee, the ACR recommends the use of topical NSAIDs, rather than oral NSAIDs. Acetaminophen, oral NSAIDs, tramadol, or intra-articular corticosteroid injections are recommended first-line pharmacologic therapies for osteoarthritis of the hip. In contrast to the AAOS and NICE guidelines, the new ACR guidelines do not comment on therapy options for patients at high risk for oral NSAID-related gastrointestinal adverse events; presumably, the recommendation for the use of topical versus oral NSAIDs in persons aged 75 years or older is based, at least in part, on the established increased risk of oral NSAID-related gastrointestinal and cardiovascular adverse events among older persons. ${ }^{11}$

\section{Topical NSAID formulations}

In addition to the potential decreased risk for systemic adverse events, topical NSAIDs provide opportunities for joint-targeted therapy. Elderly patients have been shown to prefer topical NSAIDs, based on the perception that a lower dose of the medication would be distributed throughout the body and therefore may result in less toxicity. ${ }^{12}$ Topical NSAIDs also can be compounded to customize treatments for patients; however, the efficacy of compounded topical treatments has not yet been widely studied.

Diclofenac is the only NSAID approved for topical use in the United States. Available formulations are the diclofenac epolamine topical patch $1.3 \%$, diclofenac sodium topical gel $1 \%$, and diclofenac sodium topical solution $1.5 \% \mathrm{w} / \mathrm{w}$; however, only diclofenac sodium topical gel and diclofenac sodium topical solution are specifically approved by the United States Food and Drug Administration for the treatment of osteoarthritis.

\section{Diclofenac sodium topical gel}

Diclofenac sodium topical gel is approved for pain relief from osteoarthritis of joints that are amenable to topical treatment, such as the knee or hand. ${ }^{13}$ Placebo-controlled trials support the efficacy of diclofenac sodium topical gel in this indication. ${ }^{14,15}$ A pooled analysis of 1426 patients with mild to moderate osteoarthritis of the knee from three placebocontrolled studies showed that diclofenac sodium topical gel demonstrated significantly better efficacy in comparison with placebo. In general, application-site dermatitis was the most common adverse event, and gastrointestinal adverse events were rare. ${ }^{16}$ Although diclofenac sodium topical gel has been well studied versus placebo, head-to-head comparisons with oral diclofenac in the treatment of osteoarthritis of the knee are lacking.

\section{Diclofenac sodium topical solution}

Diclofenac sodium topical solution, with the penetration enhancer dimethyl sulfoxide, is approved for use in the United States for the signs and symptoms of osteoarthritis of the knee. ${ }^{17}$ In randomized, controlled studies of patients with osteoarthritis of the knee, diclofenac sodium topical solution demonstrated significantly better efficacy in pain relief in comparison with placebo or dimethyl sulfoxide vehicle. In addition, diclofenac sodium topical solution was more effective in treating symptoms such as stiffness and in improving physical function. ${ }^{18-21}$ Diclofenac sodium topical solution also has been shown to have efficacy similar to that of oral NSAIDs. ${ }^{21,22}$ Overall, $6.5 \%$ of subjects receiving 
diclofenac sodium topical solution reported any digestive system event, whereas $23.8 \%$ of patients on oral diclofenac reported digestive events that ranged from abdominal pain to diarrhea and nausea. ${ }^{21}$ A pooled analysis of data from seven randomized, controlled trials in 1252 patients who were treated with diclofenac sodium topical solution for 4-12 weeks for the management of osteoarthritis of the hand or knee showed that dyspepsia was the most common gastrointestinal reaction (diclofenac sodium topical solution $7.7 \%$; placebo $2.9 \%$ ). The most frequently reported gastrointestinal severe adverse reactions in the diclofenac sodium topical solution group were dyspepsia $(0.4 \%)$, nausea $(0.4 \%)$, upper abdominal pain $(0.3 \%)$, breath odor $(0.2 \%)$, diarrhea $(0.2 \%)$, and vomiting $(0.2 \%){ }^{23}$

\section{Other topical analgesics}

Other topical treatments exist but have not been studied as extensively as topical NSAIDs for use by patients with osteoarthritis. The most commonly used is the lidocaine patch, an adhesive patch formulated with 5\% lidocaine and typically used as a local anesthetic, which is applied to the affected area for an analgesic effect. ${ }^{24}$ The lidocaine patch is indicated for the treatment of pain associated with postherpetic neuralgia, ${ }^{24}$ and has been specifically studied in patients with osteoarthritis. ${ }^{25}$ Less is known about the efficacy of some over-the-counter options used for short-term relief; these include topical products containing camphor, menthol, or methyl salicylates. Without randomized, controlled trials in osteoarthritis, it is unclear what effect these agents have.

\section{Future direction}

In determining treatment for patients with osteoarthritis, individualized therapy is paramount. Consideration of disease progression, pattern of flares, level of functional impairment or disability, response to treatment, coexisting conditions such as cardiovascular disease or gastrointestinal disorders, and concomitant prescription medication use should be considered when creating a therapeutic plan for a patient with osteoarthritis. ${ }^{26}$ Although topical NSAIDs historically have not been prevalent in many of the guidelines for osteoarthritis treatment, recent evidence-based medicine and new guidelines now support their use as a viable option for the clinician seeking alternatives to typical oral formulations, particularly for older patients and for patients with an increased risk of oral NSAID-related gastrointestinal and cardiovascular adverse events. A recent review of published literature on the use of topical therapies for osteoarthritis likewise concluded that topical NSAIDs are safe and efficacious in the treatment of osteoarthritis. ${ }^{27}$ Although few studies have directly compared the efficacy of topical versus oral NSAIDs, the available evidence demonstrates comparable efficacy. ${ }^{21,22}$ With an increase in products coming to market, topical NSAIDs are emerging as an important therapeutic alternative for patients with osteoarthritis.

\section{Acknowledgments}

Technical editorial and medical writing support was provided by Synchrony Medical Communications, LLC. Funding for this support was provided by Mallinckrodt Inc, a Covidien company.

\section{Disclosure}

The author has served on a speakers' bureau for Eli Lilly and Company, Endo Pharmaceuticals Inc, Forest Pharmaceuticals, Inc, Ortho-McNeil Pharmaceutical, Inc, and Pfizer Inc; has received a grant for research from Pfizer Inc; and has served as an advisory board member/consultant for Covidien, Eli Lilly and Company, Endo Pharmaceuticals Inc, Ortho-McNeil Pharmaceutical, Inc, Pfizer Inc, and Purdue Pharma LP.

\section{References}

1. Lawrence RC, Felson DT, Helmick CG, et al. Estimates of the prevalence of arthritis and other rheumatic conditions in the United States. Part II. Arthritis Rheum. 2008;58(1):26-35.

2. Kotlarz H, Gunnarsson CL, Fang H, Rizzo JA. Insurer and out-of-pocket costs of osteoarthritis in the US: evidence from national survey data. Arthritis Rheum. 2009;60(12):3546-3553.

3. Centers for Disease Control and Prevention. August 27, 2007. Arthritis types: osteoarthritis. Available from: http:/www.cdc.gov/arthritis/ basics/osteoarthritis.htm. Accessed August 24, 2011.

4. Centers for Disease Control and Prevention. Prevalence of doctordiagnosed arthritis and arthritis-attributable activity limitation - United States, 2007-2009. MMWR Morb Mortal Wkly Rep. 2010;59(39): 1261-1265.

5. Felson DT. Developments in the clinical understanding of osteoarthritis. Arthritis Res Ther. 2009;11(1):203.

6. Altman RD. New guidelines for topical NSAIDs in the osteoarthritis treatment paradigm. Curr Med Res Opin. 2010;26(12):2871-2876.

7. Barkin RL, Beckerman M, Blum SL, Clark FM, Koh EK, Wu DS. Should nonsteroidal anti-inflammatory drugs (NSAIDs) be prescribed to the older adult? Drugs Aging. 2010;27(10):775-789.

8. American Academy of Orthopaedic Surgeons. Treatment of Osteoarthritis of the Knee (Non-Arthroplasty). Rosemont, IL: American Academy of Orthopaedic Surgeons; 2008.

9. National Collaborating Centre for Chronic Conditions. Osteoarthritis: National Clinical Guideline for Care and Management in Adults. London: Royal College of Physicians; 2008. Available from: http:// www.nice.org.uk/nicemedia/pdf/CG059FullGuideline.pdf. Accessed July $18,2011$.

10. Hochberg MC, Altman RD, April KT, et al. American College of Rheumatology 2012 recommendations for the use of nonpharmacologic and pharmacologic therapies in osteoarthritis of the hand, hip, and knee. Arthritis Care Res (Hoboken). 2012;64(4):465-474.

11. Makris UE, Kohler MJ, Fraenkel L. Adverse effects of topical nonsteroidal antiinflammatory drugs in older adults with osteoarthritis: a systematic literature review. J Rheumatol. 2010;37(6):1236-1243. 
12. Carnes D, Anwer Y, Underwood M, Harding G, Parsons S. Influences on older people's decision making regarding choice of topical or oral NSAIDs for knee pain: qualitative study. BMJ. 2008; 336(7636):142-145.

13. Voltaren ${ }^{\circledR}$ Gel (diclofenac sodium topical gel) 1\% [prescribing information]. Chadds Ford, PA: Endo Pharmaceuticals Inc; 2009.

14. Barthel HR, Haselwood D, Longley S 3rd, Gold MS, Altman RD. Randomized controlled trial of diclofenac sodium gel in knee osteoarthritis. Semin Arthritis Rheum. 2009;39(3):203-212.

15. Niethard FU, Gold MS, Solomon GS, et al. Efficacy of topical diclofenac diethylamine gel in osteoarthritis of the knee. J Rheumatol. 2005;32(12):2384-2392.

16. Baraf HS, Gloth FM, Barthel HR, Gold MS, Altman RD. Safety and efficacy of topical diclofenac sodium gel for knee osteoarthritis in elderly and younger patients: pooled data from three randomized, double-blind, parallel-group, placebo-controlled, multicentre trials. Drugs Aging. 2011;28(1):27-40.

17. Pennsaid ${ }^{\circledR}$ (diclofenac sodium topical solution) $1.5 \% \mathrm{w} / \mathrm{w}$ [prescribing information]. Hazelwood, MO: Mallinckrodt Brand Pharmaceuticals, Inc; 2010.

18. Baer PA, Thomas LM, Shainhouse Z. Treatment of osteoarthritis of the knee with a topical diclofenac solution: a randomised controlled, 6-week trial [ISRCTN53366886]. BMC Musculoskelet Disord. 2005;6:44.

19. Bookman AA, Williams KS, Shainhouse JZ. Effect of a topical diclofenac solution for relieving symptoms of primary osteoarthritis of the knee: a randomized controlled trial. CMAJ. 2004;171(4):333-338.
20. Roth SH, Shainhouse JZ. Efficacy and safety of a topical diclofenac solution (Pennsaid) in the treatment of primary osteoarthritis of the knee: a randomized, double-blind, vehicle-controlled clinical trial. Arch Intern Med. 2004;164(18):2017-2023.

21. Simon LS, Grierson LM, Naseer Z, Bookman AA, Shainhouse JZ. Efficacy and safety of topical diclofenac containing dimethyl sulfoxide (DMSO) compared with those of topical placebo, DMSO vehicle and oral diclofenac for knee osteoarthritis. Pain. 2009;143(3): 238-245.

22. Tugwell PS, Wells GA, Shainhouse JZ. Equivalence study of a topical diclofenac solution (Pennsaid) compared with oral diclofenac in symptomatic treatment of osteoarthritis of the knee: a randomized controlled trial. J Rheumatol. 2004;31(10):2002-2012.

23. Roth SH, Fuller P. Diclofenac sodium topical solution $1.5 \% \mathrm{w} / \mathrm{w}$ with dimethyl sulfoxide compared with placebo for the treatment of osteoarthritis: pooled safety results. Postgrad Med. 2011;123(6):180-188.

24. Lidoderm ${ }^{\circledR}$ (lidocaine patch $5 \%$ ) [prescribing information]. Chadds Ford, PA: Endo Pharmaceuticals Inc; 2010.

25. Gammaitoni AR, Galer BS, Onawola R, Jensen MP, Argoff CE. Lidocaine patch $5 \%$ and its positive impact on pain qualities in osteoarthritis: results of a pilot 2-week, open-label study using the Neuropathic Pain Scale. Curr Med Res Opin. 2004;20(Suppl 2):S13-S19.

26. Brabant T, Stichtenoth D. Pharmacological treatment of osteoarthritis in the elderly. Z Rheumatol. 2005;64(7):467-472. German.

27. Altman RD, Barthel HR. Topical therapies for osteoarthritis. Drugs. 2011;71(10):1259-1279.
Journal of Multidisciplinary Healthcare

\section{Publish your work in this journal}

The Journal of Multidisciplinary Healthcare is an international, peerreviewed open-access journal that aims to represent and publish research in healthcare areas delivered by practitioners of different disciplines. This includes studies and reviews conducted by multidisciplinary teams as well as research which evaluates the results or conduct of such teams or

\section{Dovepress}

healthcare processes in general. The journal covers a wide range of areas and welcomes submission from practitioners at all levels, from all over the world. The manuscript management system is completely online and includes a very quick and fair peer-review system. Visit http://www.dovepress.com/testimonials.php to read real quotes from published authors. 